\title{
Influence of Diabetes on Circulating Apoptotic Microparticles in Patients with Chronic Hepatitis C
}

\author{
JOLANTA ZUWALA-JAGIELLO ${ }^{1}$, MONIKA PAZGAN-SIMON ${ }^{2}$, \\ EUGENIA MURAWSKA-CIALOWICZ ${ }^{3}$ and KRZYSZTOF SIMON ${ }^{2}$ \\ ${ }^{1}$ Department of Pharmaceutical Biochemistry, Wroclaw Medical University, Wroclaw, Poland; \\ ${ }^{2}$ Infectious Disease Department, Division of Infectious Disease and Hepatology \\ Wroclaw Medical University, Wroclaw, Poland; \\ ${ }^{3}$ Department of Physiology and Biochemistry, University of Physical Education, Wroclaw, Poland
}

\begin{abstract}
Background/Aim: Type 2 diabetes mellitus (DM) frequently occurs in patients with chronic hepatitis $C$ $(\mathrm{CHC})$ and is associated with atherosclerosis, in which circulating microparticles (MPs) play an important role. We asked whether the presence of DM affects endothelialderived (EMPs) and platelet-derived microparticles (PMPS) levels; and whether MPs levels associate with biomarkers of inflammation and oxidative stress in patients with $\mathrm{CHC}$. Materials and Methods: Overall, 136 patients were enrolled in the study, 86 CHC patients (41 with DM with moderate glycemic control), 20 outpatients with DM and 30 controls. Circulating MPs were phenotyped by flow cytometry. Results: When the MPs levels were analyzed individually in CHC patients, there was a positive association of plasma apoptotic MPs with oxidative stress markers. We report a hitherto undescribed relationship between diabetes prevalence and apoptotic MPs-associated inflammation in patients with CHC. Conclusion: The presence of apoptotic MPs in the plasma of CHC patients, with increased levels being found in patients with DM and moderate glycemic control was herein demonstrated. The simultaneous monitoring of plasma apoptotic MPs, oxidative stress markers and inflammatory biomarkers can be helpful for the cardiovascular disease control in diabetic patients with $\mathrm{CHC}$.
\end{abstract}

This article is freely accessible online.

Correspondence to: Jolanta Zuwala-Jagiello, Department of Pharmaceutical Biochemistry, Wroclaw Medical University, 211 Borowska Street, 50-556 Wroclaw, Poland. Tel: +48 0717840303, e-mail: jolanta.zuwala-jagiello@umed.wroc.pl

Key Words: Chronic hepatitis C, apoptotic microparticles, inflammation, diabetes.
Chronic hepatitis C (CHC) infection remains a severe lifethreatening medical and public health problem. The vast majority of patients with chronic hepatitis $\mathrm{C}$ infection have not yet been diagnosed and remain untreated. As this group gets older, the burden of HCV-related extrahepatic manifestations is expected to increase tremendously. Of these, there is increasing evidence that $\mathrm{CHC}$ infection increases the risk for insulin resistance and type 2 diabetes mellitus (DM) $(1,2)$. The association between hepatitis $\mathrm{C}$ virus (HCV) and type 2 diabetes has been shown to be related both to the host factors as well as viral factors (3). In fact, $\mathrm{HCV}$ has been shown to affect glucose-insulin homeostasis and lipid metabolism. In addition, viral factors (HCV genotypes and $\mathrm{HCV}$ core protein) can have a direct impact on these interactions (3). There are significant evidences to support the notion that $\mathrm{HCV}$ predisposes patients to type 2 diabetes and also the burden of cardiovascular diseases increases in CHC patients $(4,5)$.

Circulating microparticles (MPs) including endothelialderived and platelet-derived mircoparticles (EMPs and PMPs, respectively) are submicron plasma membrane vesicles released from the cell plasma membrane in response to numerous conditions, including activation and apoptosis (6). Furthermore, many stimuli that promote MPs release, including oxidative stress (7) and systemic inflammation (8), are present in liver diseases. EMPs derived from activated endothelial cells may have pro-angiogenic and cardioprotective properties. In opposite, apoptotic EMPs that originated from damaged endothelial cells are discussed as markers of endothelial cell injury (9). They are found in the blood of healthy subjects and their level increases in many pathologies, especially in metabolic disorders, such as DM and cardiovascular diseases $(10,11)$. There is increasing evidence of the importance of platelets in the early stages of vascular injury leading to atherosclerosis (12). Additionally, different reports have described that PMPs can enhance the 
expression of adhesion molecules on endothelial cells and contribute functional effects in terms of conditions involved in atherosclerosis (namely, inflammation and coagulation) $(13,14)$. The number of circulating PMPs may vary in different inflammatory and cardiovascular diseases, reflecting the interaction of the pathological process with the endothelium. Indeed, it has been demonstrated that circulating PMPs are a marker of cardiovascular diseases $(15,16)$ and are elevated in patients with chronic hepatitis (17) and diabetes (18).

Recent studies have reported changes in some MPs levels in patients with chronic hepatitis (19, 20, 21). However inconsistent conclusions, relating predominantly to methodological issues were reported in these studies. Moreover, none of these studies investigated possible associations between circulating EMPs and PMPs levels and both oxidative stress and inflammation in chronic hepatitis. The present study addressed the hypothesis that the presence of DM in patients with $\mathrm{CHC}$ may alter the circulating level of MPs including endothelialderived and platelet-derived mircoparticles.

The aim of this study was to evaluate the associations between DM and circulating MPs including endothelialderived and platelet-derived mircoparticles, plasma oxidative stress markers (CML-AGEs, oxidative stress index) and inflammatory biomarkers (hsCRP, IL-6, TNF- $\alpha$ ) in CHC patients, comparing diabetic and non-diabetic patients with a control group with type 2 diabetes mellitus.

\section{Patients and Methods}

Patients and study design. This study was performed in 86 patients with chronic hepatitis $\mathrm{C}$ (CHC) infection admitted to the Clinic of Infectious Diseases, Liver Diseases and Acquired Immune Deficiency for evaluation. Patients were divided into two groups according to their HCV antibody status and the presence of type 2 diabetes mellitus: anti-HCV-positive diabetic patients $(n=41)$ and anti-HCV-positive non-diabetic patients. $(n=45)$. The control group with type 2 diabetes mellitus (DM controls) was comprised of diabetic outpatients $(n=20,12$ males $/ 8$ females, mean age $59 \pm 10.4$ years $)$.

The exclusion criteria were as follows. 1) Liver cirrhosis. 2) Conditions other than diabetes and HCV infection that could influence either serum glucose levels: premenopausal women; alcohol consumption $>40 \mathrm{~g} /$ day; treatment with steroid or nonsteroidal anti-inflammatory drugs, except aspirin; concomitant infection; and chronic diseases other than diabetes. 3) Hypertension, cardiovascular diseases, autoimmune or malignant diseases, anticoagulation or antiplatelet therapy. 4) Type 1 diabetes (history of diabetic ketoacidosis or age $<30$ years with insulin requirement) and secondary diabetes due to chronic pancreatitis or pancreatic tumor. Liver cirrhosis was ruled out by liver biopsy performed within 18 months before inclusion (compensated patients) or by typical clinical features such as signs of portal hypertension (splenomegaly, ascites, and esophageal varices), hematologic evidence of hypersplenism, or biochemical evidence of hepatocellular failure.
The diagnosis of chronic hepatitis $\mathrm{C}$ infection was based on persistently increased alanine aminotransferase values, anti-HCV and HCV-RNA positivity and liver histology features. The HCV inflammation was confirmed by measurement of $\mathrm{HCV} \mathrm{Ab}$ and $\mathrm{HCV}$ RNA in the serum, using the EIA methods and RT PCR - Cobas Amplicor Roche methods, respectively. For the anti-HCV positive patients with normal aminotransferase levels and no liver biopsy, we ensured that aminotransferase levels, and liver function tests results were persistently normal.

Participants were classified as having DM if they met the 2006 American Diabetes Association criteria: Fasting Blood Glucose (FBG) $>126 \mathrm{mg} / \mathrm{dl}$, a doctor's diagnosis of diabetes and/or on medication for diabetes. No diabetes was defined as absence of a history of DM and FBG $<100 \mathrm{mg} / \mathrm{dl}$ (1). All diabetic subjects in the present study had moderate hyperglycemia (HbA1c, 6-8\%).

All laboratory measurements were performed on fasting blood samples. After $2 \mathrm{~h}$ of bed rest, blood pressure was determined with an automatic digital sphygmomanometer and blood samples were collected in ice-cooled, ethylenediaminetetraacetic acid (EDTA)containing tubes for the determination of plasma CML, in tubes with no additive for routine biochemical study and cytokine concentrations. All samples were separated immediately by centrifugation at $4^{\circ} \mathrm{C}$ and stored at $-80^{\circ} \mathrm{C}$ until further analysis.

Assessment of plasma circulating MPs. The circulating microparticles (MPs) were categorized into (1 platelet-derived activated MPs (PMPs-ac) $\left(\mathrm{CD} 31^{+} \mathrm{CD} 42 \mathrm{~b}^{+} \mathrm{AN}-\mathrm{V}^{-}\right)$, 2) platelet derived apoptotic MPs (PMPs-ap) $\left.\left(\mathrm{CD} 31^{+} \mathrm{CD} 42 \mathrm{~b}^{+} \mathrm{AN}-\mathrm{V}^{+}\right), 3\right)$ endothelial-derived activated MPs (EMPs-ac) $\left(\mathrm{CD} 31^{+} \mathrm{CD} 42 \mathrm{~b}^{-} \mathrm{AN}-\right.$ $\mathrm{V}-$ ), and 4) endothelial-derived apoptotic MPs (EMPs-ap) (CD31+ $\mathrm{CD}_{42 \mathrm{~b}^{-}} \mathrm{AN}-\mathrm{V}^{+}$) based on a previous report (22) with some modifications. Blood collection was performed in the morning in overnight fasting patients and constrols. Peripheral blood was collected in acid citrate dextrose vacutainer tubes, using a 21-gauge needle. The first $3 \mathrm{ml}$ of blood were discarded to avoid contamination with EMPs due to vascular injury (23). The peripheral blood $(1.5 \mathrm{ml})$ was centrifuged at $2,500 \mathrm{~g}$ at $4^{\circ} \mathrm{C}$ for 15 min without acceleration or break to prepare platelet-rich plasma. The $250 \mu \mathrm{L}$ plasma samples were thawed and centrifuged for $10 \mathrm{~min}$ at $19,700 \mathrm{~g}$ at $4^{\circ} \mathrm{C}$ and then collected for investigation of microparticles smaller than $1.0 \mu \mathrm{m}$. Size calibration was conducted with $1.0 \mu \mathrm{m}$ beads. The MPs pellet was resuspended with $150 \mu \mathrm{l}$ of Annexin- $\mathrm{V}$ binding buffer (BD Biosciences, San Jose, CA, USA). All buffers were sterile-filtered with a $0.2 \mu \mathrm{m}$ filter. The $100 \mu \mathrm{L}$ MPs were then incubated in a TruCOUNT tube (BD Biosciences, San Jose, CA, USA) with fluorescent monoclonal antibodies: anti-CD31- PE, Anti-annexin-V-FITC, and anti-CD42bPE (BD Biosciences, San Jose, CA, USA). The samples were incubated in the dark for $15 \mathrm{~min}$ at room temperature. The samples were then analyzed on a FC500 flow cytometer (Beckman Coulter) after $400 \mu \mathrm{L}$ Annexin-V binding buffer was added. The absolute count of MPs was measured setting the stop condition for TruCount beads at 100,000 events. Fluorescence minus controls and nonstained samples were used to discriminate true events from noise, and to increase the specificity for MPs detection. The contamination of $\mathrm{CD} 31^{+} \mathrm{CD} 42 \mathrm{~b}^{-}$EMPs with $\mathrm{CD} 45^{+} \mathrm{CD} 31^{+} \mathrm{CD} 42 \mathrm{~b}^{-}$ leukocyte MPs was tested using the pan-leukocyte marker CD45. The amount of $\mathrm{CD} 45^{+} \mathrm{CD} 31+\mathrm{CD} 42 \mathrm{~b}^{-}$leukocyte MPs was low (4.6\% in platelet-poor plasma). Values are reported as counts per microliter. 
Table I. Clinical and biochemical characteristics of the study groups.

\begin{tabular}{|c|c|c|c|}
\hline & Healthy controls & $\mathrm{CHC}$ patients & DM controls \\
\hline (n) & 30 & 86 & 20 \\
\hline Male:Female Ratio & $17: 13$ & 45:41 & $12: 8$ \\
\hline Age (years) & $56 \pm 8.7$ & $62 \pm 14$ & $59 \pm 10.5$ \\
\hline Systolic blood pressure (mmHg) & $129 \pm 10.5$ & $133 \pm 13.5$ & $146 \pm 11.7$ \\
\hline Diastolic blood pressure (mmHg) & $79 \pm 6.5$ & $78 \pm 6.9$ & $81 \pm 10.5$ \\
\hline Duration of hepatitis C (years) & - & $9.4 \pm 2.9$ & - \\
\hline HCV RNA (copies/mL) & - & $\begin{array}{c}3,28 \times 10^{5} \\
\left(0,021 \times 10^{5}-7,06 \times 10^{5}\right)\end{array}$ & - \\
\hline Alanine aminotransferase (IU/l) & $23(20-28)$ & $95(33-190)^{* *}$ & $25(20-27)$ \\
\hline Aspartate aminotransferase (IU/l) & $28(23-30)$ & $78(28-140)^{* *}$ & $28(21-30)$ \\
\hline Gamma-glutamyltranspeptidase (IU/1) & $26(25-29)$ & $62(41-106)^{*}$ & $26(25-30)$ \\
\hline Body mass index $\left(\mathrm{kg} / \mathrm{m}^{2}\right)$ & $21.5 \pm 2.6$ & $22.7 \pm 2.5$ & $29.5 \pm 2.6$ \\
\hline Diabetes mellitus type $2(\%)$ & - & 48 & 100 \\
\hline FBG $(\mathrm{mmol} / \mathrm{l})$ & $5.0 \pm 0.6$ & $6.1 \pm 1.9^{*}$ & $6.8 \pm 1.2 *$ \\
\hline \multicolumn{4}{|l|}{$\mathrm{HbA}_{1 \mathrm{c}}$} \\
\hline $6-7 \%$ & - & $6 \%, n=5$ & $27 \%, n=5$ \\
\hline $7-8 \%$ & - & $42 \%, n=36$ & $73 \%, n=15$ \\
\hline Total cholesterol (mg/dl) & $140 \pm 55$ & $179 \pm 43$ & $189.2 \pm 64.3$ \\
\hline Low density lipoprotein $(\mathrm{mg} / \mathrm{dl})$ & $93 \pm 31$ & $113 \pm 25$ & $135.9 \pm 44.1$ \\
\hline High density lipoprotein cholesterol (mg/dl) & $40 \pm 16$ & $45 \pm 10$ & $39 \pm 15$ \\
\hline Triglycerides $(\mathrm{mg} / \mathrm{dl})$ & $42 \pm 10$ & $46 \pm 11$ & $82 \pm 22$ \\
\hline Albumin $(\mathrm{g} / \mathrm{dl})$ & $4.8(3.6-5.7)$ & $4.4(3.4-4.8)$ & $5.0(3.5-5.8)$ \\
\hline Total protein $(\mathrm{g} / \mathrm{dl})$ & $7.5(6.8-8.1)$ & $7.6(6.8-8.2)$ & $8.0(6.8-8.2)$ \\
\hline \multicolumn{4}{|l|}{ EMPs-ap } \\
\hline $\mathrm{CD} 1^{+} \mathrm{CD}^{2} \mathrm{bb}^{-} \mathrm{AN}-\mathrm{V}^{+}$(counts $\left./ \mu \mathrm{l}\right)$ & $4.8(0.0-10.4)$ & $11.6(0.0-20.7)^{*}$ & $23.5(0.0-42.5)^{* *+}$ \\
\hline \multicolumn{4}{|l|}{ EMPs-ac } \\
\hline $\mathrm{CD} 31^{+} \mathrm{CD} 42 \mathrm{~b}^{-} \mathrm{AN}-\mathrm{V}^{-}($counts $/ \mu \mathrm{l})$ & $0.71(0.0-0.76)$ & $3.4(0.0-19.8)$ & $7.3(0.0-8.1)$ \\
\hline \multicolumn{4}{|l|}{ PMPs-ap } \\
\hline $\mathrm{CD} 31^{+} \mathrm{CD} 42 \mathrm{~b}^{+} \mathrm{AN}-\mathrm{V}^{+}($counts $/ \mu \mathrm{l})$ & $4.58(0.0-11.01)$ & $11.07(0.0-39.7) *$ & $28.0(5.8-54.7)^{* * *+}$ \\
\hline \multicolumn{4}{|l|}{ PMPs-ac } \\
\hline $\mathrm{CD} 31^{+} \mathrm{CD} 42 \mathrm{~b}^{+} \mathrm{AN}-\mathrm{V}^{-}($counts $/ \mu \mathrm{l})$ & $6.45(0.0-15.5)$ & $120.0(0.0-128.0)$ & $80.2(0.0-101.0)$ \\
\hline
\end{tabular}

Values are expressed as means $\pm \mathrm{SD}$ or as medians (interquartile range) for skewed data. Statistical significance: $* p<0.05 ; * * p<0.01 v s$. healthy controls; $+p<0.01 v s$. CHC patients. CML-AGEs: Ne-(carboxymethyl)lysine-advanced glycation end products; EMP-ac: endothelial-derived activated microparticles (CD31+ $\left.\mathrm{CD}^{2} \mathrm{~b}^{-} \mathrm{AN}-\mathrm{V}^{-}\right)$; EMP-ap: endothelial-derived apoptotic microparticles (CD31+ $\left.\mathrm{CD}^{2} \mathrm{~b}^{-} \mathrm{AN}-\mathrm{V}^{+}\right)$; FBG: fasting blood glucose; PMPs-ac: platelet-derived activated MPs $\left(\mathrm{CD} 31^{+} \mathrm{CD} 42 \mathrm{~b}^{+} \mathrm{AN}-\mathrm{V}^{-}\right)$; PMPs-ap: platelet derived apoptotic MPs $\left(\mathrm{CD} 31^{+} \mathrm{CD} 42 \mathrm{~b}^{+} \mathrm{AN}-\mathrm{V}^{+}\right)$.

Biochemical assays. Plasma Ne-(carboxymethyl)lysine (CML) levels were determined using a specific competitive ELISA kit (CircuLex CML/Ne-(carboxymethyl)lysine ELISA Kit (CycLex Co., Ltd, Nagano, Japan)). The plasma antioxidant capacity was measured using a commercially available total antioxidant status TAS kit (Randox Laboratories, Crumlin, UK). The percent ratio of the CML-AGEs level to the TAS level gave the oxidative stress index (OSI), an indicator of the degree of oxidative stress. Serum levels of TNF- $\alpha$ and IL- 6 were assayed with enzyme-linked immunosorbent assay (ELISA) kits (R\&D Systems Inc., Minneapolis, MN, USA) according to the manufacturer's instructions. The minimum detection levels were $1.6 \mathrm{pg} / \mathrm{ml}$ and $<0.70 \mathrm{pg} / \mathrm{ml}$ for TNF- $\alpha$ and IL-6, respectively. Serum highsensitivity C-reactive protein (hsCRP) level was determined by a high-sensitivity nephelometric method using the Beckman Image Immunochemistry system (Beckman Instruments, Fullerton, CA, USA), which has a minimum detection level of $0.2 \mathrm{mg} / \mathrm{L}$. HbA1c levels were measured using ion-exchange high-performance liquid chromatography (Bio-Rad Variant ${ }^{\mathrm{TM}}$ II Turbo $\mathrm{HbA}_{1 \mathrm{c}} \mathrm{Kit}$ ). All other biochemical parameters were measured with routine laboratory methods.

Ethical aspects. The consent of the Bioethics Committee of the Wroclaw Medical University was obtained and all patients were informed about the analyses performed. Studies were conducted in compliance with the ethical standards formulated in the Helsinki Declaration of 1975 (revised in 1983).

Statistical analysis. Continuous variables are expressed as median (interquartile range (IQR)) and categorical variables as number (percentage). Unpaired data were analyzed by the independent samples $t$-test or the Mann-Whitney test. Paired data were analyzed by the paired Student $t$-test or Wilcoxon test. All reported $p$-values were two-tailed, and values $<0.05$ were considered significant. Correlation analysis between stochastically independent variables were performed by the Pearson correlation test. Multiple logistic 
in vivo $31: 1027-1034(2017)$

Table II. Clinical and biochemical variables associated with diabetes mellitus (DM).

\begin{tabular}{|c|c|c|c|}
\hline & CHC patients without diabetes & $\mathrm{CHC}$ patients with diabetes & DM controls \\
\hline (n) & 45 & 41 & 20 \\
\hline Male:Female ratio & $26: 19$ & $19: 22$ & $12: 8$ \\
\hline Age (years) & $61 \pm 12$ & $64 \pm 11$ & $59 \pm 10.5$ \\
\hline Body mass index $\left(\mathrm{kg} / \mathrm{m}^{2}\right)$ & $22 \pm 2.3$ & $23.3 \pm 2.5$ & $29.5 \pm 2.6$ \\
\hline HbA1c $(\%)$ & $5.12 \pm 0.55$ & $6.7 \pm 1.2 * *$ & $6.9 \pm 0.98 * *$ \\
\hline Alanine aminotransferase (IU/l) & $89(33-150)$ & $104(37-190)$ & $25(20-27)^{* *++}$ \\
\hline Aspartate aminotransferase (IU/l) & $76(28-130)$ & $84(31-140)$ & $28(21-30)^{*+}$ \\
\hline Albumin $(\mathrm{g} / \mathrm{dl})$ & $4.35(4.2-4.9)$ & $4.4(3.4-4.8)$ & $5.0(3.5-5.8)$ \\
\hline Platelet count $\left(\times 10^{9} / 1\right)$ & $216(154-241)$ & $214(161-245)$ & $200(130-220)$ \\
\hline WBC count $\left(\times 10^{9} / 1\right)$ & $4.9(3.0-7.8)$ & $6.4(3.3-8.2)$ & $4.7(3.2-5.0)$ \\
\hline \multicolumn{4}{|l|}{ Oxidative stress markers } \\
\hline CML-AGEs (ng/ml) & $2.7(1.7-3.6)$ & $4.4(2.5-8.2)^{* *}$ & $4.3(2.7-5.5)^{* *}$ \\
\hline TAS $(\mathrm{mmol} / \mathrm{l})$ & $1.1(0.9-1.3)$ & $0.68(0.5-0.9)^{*}$ & $0.56(0.4-0.81)^{* *}$ \\
\hline OSI (arbitrary unit) & $2.4(1.9-2.8)$ & $6.4(5.1-9.1 .)^{* *}$ & $5.7(4.4-8.0)^{* *}$ \\
\hline \multicolumn{4}{|l|}{ Inflammatory markers } \\
\hline $\mathrm{hsCRP}(\mathrm{mg} / \mathrm{l})$ & $1.74(1.05-4.5)$ & $3.9(1.5-20.1)^{* *}$ & $1.9(0.58-2.5)^{+}$ \\
\hline IL-6 (pg/ml) & $5.1(2.8-9.8)$ & $9.4(4.8-12.1)^{*}$ & $6.5(5.5-7.7)$ \\
\hline TNF- $\alpha(\mathrm{pg} / \mathrm{ml})$ & $33.0(29.0-36.0)$ & $35.0(32.0-42.3)$ & $28.0(22.0-35.0)$ \\
\hline \multicolumn{4}{|l|}{ EMPs-ap } \\
\hline $\mathrm{CD} 31^{+} \mathrm{CD} 42 \mathrm{~b}^{-} \mathrm{AN}-\mathrm{V}^{+}($counts $/ \mu \mathrm{l})$ & $8.1(0.0-11.7)$ & $14.3(2.2-20.68)^{* *}$ & $23.5(0.0-42.5)^{* * *+}$ \\
\hline \multicolumn{4}{|l|}{ EMPs-ac } \\
\hline $\mathrm{CD} 31^{+} \mathrm{CD} 42 \mathrm{~b}^{-} \mathrm{AN}-\mathrm{V}^{-}(\mathrm{counts} / \mu \mathrm{l})$ & $3.4(0.0-12.6)$ & $4.1(0.0-19.8)$ & $7.3(0.0-8.1)$ \\
\hline \multicolumn{4}{|l|}{ PMPs-ap } \\
\hline $\mathrm{CD} 31^{+} \mathrm{CD} 42 \mathrm{~b}^{+} \mathrm{AN}-\mathrm{V}^{+}($counts $/ \mu \mathrm{l})$ & $7.7(0.0-11.2)$ & $15.4(4.2-39.7)^{* *}$ & $28.0(5.8-54.7)^{* * *++}$ \\
\hline \multicolumn{4}{|l|}{ PMPs-ac } \\
\hline $\mathrm{CD} 31^{+} \mathrm{CD} 42 \mathrm{~b}^{+} \mathrm{AN}-\mathrm{V}^{-}($counts $/ \mu \mathrm{l})$ & $79.0(0.0-119.0)$ & $125.0(0.0-128.0)$ & $80.2(0.0-101.0)$ \\
\hline
\end{tabular}

Values are expressed as means $\pm \mathrm{SD}$ or as medians (interquartile range) for skewed data. Significance levels between groups: $* p<0.05$; $* * p<0.01$, $* * * p<0.001 v s$. CHC patients without diabetes; ${ }^{+} p<0.01,{ }^{++} p<0.001 v s$. CHC patients with diabetes. CML-AGEs: Ne-(carboxymethyl)lysineadvanced glycation end products; EMP-ac: endothelial-derived activated microparticles $\left(\mathrm{CD} 31^{+} \mathrm{CD}_{2} 2 \mathrm{~b}^{-} \mathrm{AN}-\mathrm{V}^{-}\right)$; EMP-ap: endothelial-derived apoptotic microparticles (CD31+ CD42b-AN- $\left.\mathrm{V}^{+}\right)$; FBG: fasting blood glucose; hsCRP: high sensitivity C-reactive protein; IL-6: interleukin-6; PMPs-ac: platelet-derived activated MPs $\left(\mathrm{CD} 31^{+} \mathrm{CD} 42 \mathrm{~b}^{+} \mathrm{AN}-\mathrm{V}^{-}\right)$; PMPs-ap: platelet derived apoptotic MPs $\left(\mathrm{CD} 31^{+} \mathrm{CD}_{2} \mathrm{~b}^{+} \mathrm{AN}-\mathrm{V}^{+}\right)$; $\mathrm{TAS}$ : total antioxidant status; TNF- $\alpha$ : tumor necrosis factor $\alpha$; OSI: oxidative stress index; WBC: white blood cells.

regression analysis was used to identify factors related to high MPs level. Variables that achieved statistical significance in the univariate analysis $(p$-value $<0.05)$ were subsequently included in a logistic regression analysis. Selection of variables was based on a stepwise regression analysis using a forward selection method.

\section{Results}

Clinical and biochemical characteristics of the study groups. Clinical and biochemical characteristics of the study groups are reported in detail in Table I. In all subjects (45 males/41 females, mean age $62 \pm 14$ years), diabetic outpatients belonging to the DM controls (12 males/8 females, mean age $59 \pm 10.5$ years $)$, and healthy controls ( 17 males/13 females, mean age $56 \pm 8.7$ years), age, body mass index (BMI), systolic blood pressure (SBP), diastolic blood pressure (DBP) were obtained together with measurements of albumin, various liver enzymes (ALT, AST and $\gamma$-GT), fasting blood glucose, total cholesterol, high density lipoprotein-cholesterol, low density lipoprotein-cholesterol and triglyceride concentrations (Table I). The levels of aminotransferases and $\gamma$-GT were significantly lower in DM controls compared to $\mathrm{CHC}$ patients $(p<0.05)$. There were no significant differences among the three groups with respect to gender, systolic blood pressure, diastolic blood pressure, body mass index, serum albumin, serum total protein and lipids profile (Table I). The plasma levels of MPs in the group of patients with CHC and DM controls and healthy controls are presented in Table I. Plasma MPs were also checked for correlations with selected biochemical markers of liver function (albumin, prothrombin ratio, bilirubin concentration) and injury (aminotransferases). Comparable levels of EMPs-ac $\left(\mathrm{CD} 31^{+} \mathrm{CD}_{2} \mathrm{~b}^{-} \mathrm{AN}-\mathrm{V}^{-}\right)$and PMPs-ac $\left(\mathrm{CD} 31^{+} \mathrm{CD}_{2} \mathrm{~b}^{+} \mathrm{AN}-\mathrm{V}^{-}\right)$were found in all $\mathrm{CHC}$ patients and in healthy controls, but increased levels of EMPs-ap

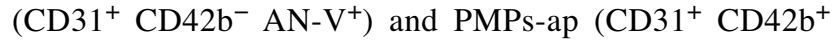
$\mathrm{AN}-\mathrm{V}^{+}$) were observed in $\mathrm{CHC}$ patients and $\mathrm{DM}$ controls 
Table III. Univariate logistic regression analysis of factors associated with high MPs-ap level in patients with chronic hepatitis $C$ (CHC) ( $n=86)$.

\begin{tabular}{|c|c|c|c|c|}
\hline & \multicolumn{2}{|c|}{ EMPs-ap $>11.6$ counts $/ \mu \mathrm{L}$} & \multicolumn{2}{|c|}{ PMPs-ap >11.07 counts $/ \mu \mathrm{L}$} \\
\hline & OR $(95 \% \mathrm{CI})$ & $p$-Value & OR $(95 \% \mathrm{CI})$ & $p$-Value \\
\hline Age (years) & $1.05(0.61-1.87)$ & 0.91 & $1.04(0.63-1.92)$ & 0.94 \\
\hline Systolic blood pressure (mmHg) & $1.13(0.72-1.92)$ & 0.63 & $1.2(0.73-2.01)$ & 0.66 \\
\hline Diastolic blood pressure $(\mathrm{mmHg})$ & $1.81(0.94-3.45)$ & 0.74 & $1.88(0.98-3.61)$ & 0.77 \\
\hline Body mass index $\left(\mathrm{kg} / \mathrm{m}^{2}\right)$ & $0.93(0.52-1.54)$ & 0.73 & $0.97(0.54-1.61)$ & 0.76 \\
\hline $\mathrm{HbA}_{1 \mathrm{c}}(\%)$ & $2.78(1.4-6.5)$ & 0.01 & $2.92(1.46-6.8)$ & 0.02 \\
\hline FBG $(\mathrm{mmol} / \mathrm{l})$ & $2.24(1.14-4.36)$ & 0.01 & $2.35(1.19-4.57)$ & 0.014 \\
\hline Type 2 diabetes mellitus & $4.12(2.25-7.75)$ & 0.001 & $4.31(2.36-8.11)$ & 0.001 \\
\hline \multicolumn{5}{|l|}{ Inflammatory markers } \\
\hline hsCRP (mg/l) & $2.45(1.22-5.13)$ & 0.01 & $2.53(1.28-5.37)$ & 0.01 \\
\hline IL-6 $(\mathrm{pg} / \mathrm{ml})$ & $2.32(1.05-5.56)$ & 0.05 & $2.43(1.10-5.82)$ & 0.05 \\
\hline \multicolumn{5}{|l|}{ Oxidative stress markers } \\
\hline CML-AGEs (ng/ml) & $1.91(1.13-3.52)$ & 0.03 & $2.0(1.18-3.69)$ & 0.05 \\
\hline OSI (arbitrary unit) & $2.04(1.12-3.63)$ & 0.01 & $2.14(1.17-3.8)$ & 0.01 \\
\hline
\end{tabular}

CI: Confidence interval; CML-AGEs: Ne-(carboxymethyl)lysine-advanced glycation end products; EMP-ap: endothelial-derived apoptotic microparticles $\left(\mathrm{CD} 31^{+} \mathrm{CD}_{2} \mathrm{~b}^{-} \mathrm{AN}-\mathrm{V}^{+}\right)$; FBG: fasting blood glucose; hsCRP: high sensitivity C-reactive protein; IL-6: interleukin-6; PMPs-ap: platelet derived apoptotic MPs $\left(\mathrm{CD} 31^{+} \mathrm{CD} 42 \mathrm{~b}^{+} \mathrm{AN}-\mathrm{V}^{+}\right)$; TAS: total antioxidant status; TNF- $\alpha$ : tumor necrosis factor $\alpha$; OR: odds ratio; OSI: oxidative stress index.

Table IV. Multiple logistic regression analysis of factors associated with high MPs-ap level in patients with chronic hepatitis C (CHC) infection $(n=86)$.

\begin{tabular}{lccccc}
\hline & \multicolumn{2}{c}{ EMPs-ap $\geq 11.6$ counts $/ \mu \mathrm{L}$} & & PMPs-ap $\geq 11.07$ counts $/ \mu \mathrm{L}$ \\
\cline { 2 - 3 } & OR $(95 \% \mathrm{CI})$ & $p$-Value & & OR (95\% CI) & $p$-Value \\
\hline Type 2 diabetes mellitus & $3.27(1.73-6.77)$ & 0.01 & $3.42(1.81-7.1)$ & 0.01 \\
\hline
\end{tabular}

CI: Confidence interval; EMP-ap: endothelial-derived apoptotic microparticles (CD31+ $\left.\mathrm{CD}_{2} \mathrm{~b}^{-} \mathrm{AN}-\mathrm{V}^{+}\right)$; PMPs-ap: platelet derived apoptotic MPs $\left(\mathrm{CD} 31^{+} \mathrm{CD} 42 \mathrm{~b}^{+} \mathrm{AN}-\mathrm{V}^{+}\right)$; OR: odds ratio.

(Table I). In the study group of patients with $\mathrm{CHC}$, no significant correlations were observed between MPs and biochemical markers of liver function and injury (not reported in detail).

Clinical and biochemical variables associated with diabetes mellitus (DM). The plasma levels of circulating PMPs with immune phenotypes labeled as $\mathrm{CD} 1^{+} \mathrm{CD} 42 \mathrm{~b}^{+} \mathrm{AN}-\mathrm{V}^{+}$ (PMPs-ap) and $\mathrm{CD}_{3} 1^{+} \mathrm{CD}_{2} 2 \mathrm{~b}^{+} \mathrm{AN}^{-} \mathrm{V}^{-}$(PMPs-ac) and EMPs-ap $\left(\mathrm{CD} 31^{+} \mathrm{CD} 42 \mathrm{~b}^{-} \mathrm{AN}-\mathrm{V}^{+}\right)$and EMPs-ac $\left(\mathrm{CD} 31^{+}\right.$ $\mathrm{CD}_{42} \mathrm{~b}^{-} \mathrm{AN}-\mathrm{V}^{-}$) in group of patients with $\mathrm{CHC}$ and $\mathrm{DM}$ controls are presented in Table II. Distribution of sex was similar among groups. However, there was a difference in age among groups; subjects in CHC group with and without DM were older than subjects in DM controls $(p>0.05)$. Additionally, the white blood cells and platelet counts did not differ between the three groups. HbAlc levels were higher in
CHC patients with DM and DM controls than in $\mathrm{CHC}$ patients without DM $(p<0.01$, respectively), and aminotransferase levels were higher in $\mathrm{CHC}$ patients with and without DM than in DM controls (Table II). The circulating levels of EMPs-ac and PMPs-ac did not differ between the three groups, whereas the circulating levels of EMPs-ap and PMPs-ap were significantly higher in the diabetic CHC group and DM controls than in the non-diabetic CHC group ( $p<0.01, p<0.001$, respectively) (Table II). Furthermore, plasma CML-AGEs concentrations were higher in $\mathrm{CHC}$ patients with DM ( $\mathrm{n}=41$, median $4.4 \mathrm{ng} / \mathrm{mL}$, IQR 2.5-8.2 $\mathrm{ng} / \mathrm{mL}$ ) than in patients without DM, and this difference was statistically significant $(p<0.01)$. Moreover, CML-AGEs levels in diabetic CHC patients were similar to those in the DM controls (Table II). Meanwhile, the TAS values were lower, while the OSI values were significantly higher $(p<0.001)$ in the CHC patients with DM than in those with 
CHC but without DM. The median hsCRP levels were higher in the CHC patients with DM than in the DM controls (3.9 $\mathrm{mg} / \mathrm{l}$ vs. $1.9 \mathrm{mg} / \mathrm{l}$, respectively; $p<0.01$ ). Significant difference was observed in serum levels of hsCRP between CHC patients with and without DM $(p<0.01)$. IL-6 plasma concentrations were increased in the non-diabetic and diabetic CHC group, with higher concentrations in the latter $(p<0.05)$, but both groups did not differ from the DM controls (Table II). Serum TNF- $\alpha$ levels in CHC patients with and without DM were similar to those in the DM controls.

Correlations between high levels MPs-ap and low-grade inflammation, age and diabetes mellitus (DM) prevalence in patients with $\mathrm{CHC}$. The correlations between high levels of MPs-ap and relevant baseline variables in the all $\mathrm{CHC}$ patients were investigated. The positive relationships were between DM and both CML-AGEs, as well as OSI $(p<0.001, p<0.01 ;$ respectively). Moreover, significant relationships between diabetes and both hsCRP as well as IL-6 ( $p<0.01$, respectively) were observed among the CHC patients. The univariate logistic-regression analyses showed that increased levels of FBG, HbA1c, hsCRP, IL-6, CMLAGEs, high OSI, and the presence of DM were significant predictors of high MPs-ap level in patients with CHC (Table III). In contrast, there were no significant correlations between high MPs-ap levels and age, systolic or diastolic blood pressure, and body mass index. Based on stepwise multiple logistic regression analysis of factors (FBG, HbA1c, hsCRP, IL-6, CML-AGEs, OSI, and the presence of DM) the presence of DM was found to be an independent predictor of high levels of circulating EMPs-ap $(\mathrm{OR}=3.27$, 95\% CI $=1.73-6.77, \quad p<0.01)$ and PMPs-ap $(\mathrm{OR}=3.42$, $95 \% \mathrm{CI}=1.81-7.1, p<0.01)($ Table IV).

\section{Discussion}

In our study, comparable levels of EMPs-ac $\left(\mathrm{CD} 31^{+} \mathrm{CD} 42 \mathrm{~b}^{-}\right.$ $\left.\mathrm{AN}-\mathrm{V}^{-}\right)$and PMPs-ac $\left(\mathrm{CD} 31^{+} \mathrm{CD} 42 \mathrm{~b}^{+} \mathrm{AN}-\mathrm{V}^{-}\right)$were found in all CHC patients, but increased levels of EMPs-ap (CD31 ${ }^{+}$ $\left.\mathrm{CD}_{2} \mathrm{~b}^{-} \mathrm{AN}-\mathrm{V}^{+}\right)$and PMPs-ap $\left(\mathrm{CD} 31^{+} \mathrm{CD} 42 \mathrm{~b}^{+} \mathrm{AN}-\mathrm{V}^{+}\right)$ were observed in those with the DM, which may contribute to the increased atherogenic risk associated with the diabetes. Of particular interest was our finding that the presence of DM with moderate glycemic control was a significant risk factor for the presence of oxidative-driven generation of apoptotic MPs and MPs-associated inflammation in patients with $\mathrm{CHC}$.

Several causes of liver disease trigger MPs production, in particular viral infection and DM $(24,25)$. Liver disease itself might also induce MPs release, as the main processes of MPs formation (namely, apoptosis and cell activation) are common in this context $(26,27)$. This study demonstrated that circulating levels of activated EMPs and -PMPs did not differ between the two groups of $\mathrm{CHC}$ patients, whereas the circulating levels of apoptotic EMPs and -PMPs (called apoptotic MPs; MPs-ap) were significantly higher in those with diabetes. Moreover, DM was found to be a risk factor for high MPs-ap levels in all CHC patients examined. While there is ample in vitro evidence of the potential downstream biological effects of MPs (e.g., regulation of inflammation, promotion of coagulation, vascular dysfunction) $(15,9)$ many of which are known to be important in atherogenesis, in vivo data are few in patients with CHC at this juncture. Because the DM occurs in most patients with $\mathrm{CHC}$, its presence likely accounts for most of the increased prevalence of atherosclerosis in chronic hepatitis C. Subjects with poor controlled hyperglycemia, hypertension and cardiovascular diseases were excluded from our study patients. Consequently, only uncomplicated DM has remained to be an atherogenic factor along with $\mathrm{CHC}$ and emerged to be related with high MPs-ap levels.

Many stimuli that promote MPs release, including oxidative stress and systemic inflammation are present in chronic liver diseases $(7,28-30)$. In the case of DM, it has been shown that inflammation, associated with oxidative stress, predicts atherosclerosis and cardiovascular disease risk (31). On the other hand, some studies suggest that oxidative stress and apoptosis might be key factors in promoting MPs production (32). Consistently, we found that plasma oxidative stress markers (CML-AGEs, OSI) were positively correlated with both DM as well as high levels of MPs-ap in CHC patients. The above findings suggest that oxidative stress in $\mathrm{CHC}$ patients with moderate glycemic control is associated with a process of MPs formation (namely apoptosis) involving platelets and endothelial cells, including MPs-ap which may account for the pro-coagulant potential of MPs $(16,33)$. It is also possible that the oxidative-driven generation of MPs may relate to low-grade inflammation in vasculature, which associates with overproduction of cytokines (34). Finally, our results show that circulating MPs-ap levels were associated with both markers of inflammation (i.e. IL-6 and hsCRP) as well as the presence of DM. The association of MPs-ap with the low-grade inflammation suggests that inflammatory alterations are important in relation to MPs-ap elevation in CHC patients with moderate glycemic control.

The platelet-derived MPs can inflict endothelial injury via induction of inflammation and impairment of endothelialdependent vasodilation (35). The experiments in human umbilical vein endothelial cells showed that PMPs may also induce platelet/endothelial cell interaction (36), an important step in the initiation of atherosclerosis. In another report, Jansen et al. demonstrated that EMPs generated from high glucose treated cells, but not from healthy endothelial cells, induce vascular inflammation and promote atherosclerosis in vivo (37). Therefore, we suggest that an increased circulating level of apoptotic MPs in the setting of DM should be 
considered as an early indicator of atherosclerosis in $\mathrm{CHC}$ patients without a clinical history of cardiovascular disease. The exact nature of the significance of our findings, however, remains unclear.

This study is associated with a few limitations. Although the number of patients enrolled might seem small, it adequately represents the sample size estimated to provide the specific power. However, a primary limitation of the present study is its cross-sectional design and the inherent possibility that lifestyle factors may have influenced the results described here. In an effort to minimize confounding variables, we studied subjects of similar age and nonsmokers who were not currently taking medication that, could influence inflammatory and oxidative markers. Being cross-sectional in its nature, our study allows commenting only on associationspathomechanisms involved, causality or the direction of potential causal associations cannot be determined.

In conclusion, the simultaneous monitoring of plasma apoptotic MPs, oxidative stress markers and inflammatory biomarkers can be helpful for the cardiovascular disease control in $\mathrm{CHC}$ patients with moderate glycemic control. Larger prospective studies should investigate the practical clinical value of plasma apoptotic MPs measurements. As the burden of cardiovascular diseases increases in $\mathrm{CHC}$ patients, and as attempts focus on treating HCV infection worldwide, this problem requires urgent attention.

\section{References}

1 Douglas MW and George J: Molecular mechanisms of insulin resistance in chronic hepatitis C. World J Gastroenterol 15(35): 4356-4364, 2009.

2 Petit JM, Bour JB, Galland-Jos C, Minello A, Verges B, Guiguet M, Brun JM and Hillon P: Risk factors for diabetes mellitus and early insulin resistance in chronic hepatitis C. J Hepatol 35(2): 279-283, 2001.

3 Ratziu V, Heurtier A, Bonyhay L, Poynard T and Giral P: Review article: an unexpected virus-host interaction - the hepatitis C virus-diabetes link. Aliment Pharmacol Ther 22(2): 56-60, 2005

4 Adinolfi LE, Restivo L, Zampino R, Guerrera B, Lonardo A, Ruggiero L, Riello F, Loria $\mathrm{P}$ and Florio A: Chronic HCV infection is a risk of atherosclerosis. Role of $\mathrm{HCV}$ and $\mathrm{HCV}$ related steatosis. Atherosclerosis 221(2): 496-502, 2012.

5 Forde KA, Haynes K, Troxel AB, Trooskin S, Osterman MT, Kimmel SE, Lewis JD and Lo R: Risk of myocardial infarction associated with chronic hepatitis $\mathrm{C}$ virus infection: a populationbased cohort study. J Viral Hepat 19(4): 271-277, 2012.

$6 \mathrm{~J}$ Freyssinet JM and Dignat-George F: More on: Measuring circulating cell-derived microparticles. J Thromb Haemost 3(3): 613-614, 2005.

7 Miyoshi H, Umeshita K, Sakon M, Imajoh-Ohmi S, Fujitani K, Gotoh M, Oiki E, Kambayashi $\mathrm{J}$ and Monden M: Calpain activation in plasma membrane bleb formation during tert-butyl hydroperoxide-induced rat hepatocyte injury. Gastroenterology 110(6): 1897-1904, 1996.
8 Nomura S, Nakamura T, Cone J, Tandon NN and Kambayashi $\mathrm{J}$ : Cytometric analysis of high shear-induced platelet microparticles and effect of cytokines on microparticle generation. Cytometry 40(3): 173-181, 2000.

9 Rautou PE, Vion AC, Amabile N, Chironi G, Simon A, Tedgui A and Boulanger CM: Microparticles, vascular function, and atherothrombosis. Circ Res 109(5): 593-606, 2011.

10 Meziani F, Tesse A and Andriantsitohaina R: Microparticles are vectors of paradoxical information in vascular cells including the endothelium: role in health and diseases. Pharmacol Rep 60(1): 75-84, 2008.

11 Amabile N, Rautou PE, Tedgui A and Boulanger CM: Microparticles: key protagonists in cardiovascular disorders. Semin Thromb Hemost 36(8): 907-916, 2010.

12 Badimon L and Vilahur G: Thrombosis formation on atherosclerotic lesions and plaque rupture. J Intern Med 276(6): 618-632, 2014.

13 Mause SF and Weber C: Microparticles: protagonists of a novel communication network for intercellular information exchange. Circ Res 107(9): 1047-1057, 2010.

14 Suades R, Padró T, Vilahur G and Badimon L: Circulating and platelet-derived microparticles in human blood enhance thrombosis on atherosclerotic plaques. Thromb Haemost 108(6): 1208-1219, 2012.

15 VanWijk MJ, VanBavel E, Sturk A and Nieuwland R: Microparticles in cardiovascular diseases. Cardiovasc Res 59(2): 277287, 2003.

16 Puddu P, Puddu GM, Cravero E, Muscari S and Muscari A: The involvement of circulating microparticles in inflammation, coagulation and cardiovascular diseases. Can J Cardiol 26(4): 140-145, 2010.

17 Fusegawa H, Shiraishi K, Ogasawara F, Shimizu M, Haruki Y, Miyachi H, Matsuzaki S and Ando Y: Platelet activation in patients with chronic hepatitis C. Tokai J Exp Clin Med 27(4): 101-106, 2002.

18 Tsimerman G, Roguin A, Bachar A, Melamed E, Brenner B and Aharon A: Involvement of microparticles in diabetic vascular complications. Thromb Haemost 106(2): 310-321, 2011.

19 Kornek M, Popov Y, Libermann TA, Afdhal NH and Schuppan D: Human $\mathrm{T}$ cell microparticles circulate in blood of hepatitis patients and induce fibrolytic activation of hepatic stellate cells. Hepatology 53(1): 230-242, 2011.

20 Kornek M, Lynch M, Mehta SH, Lai M, Exley M, Afdhal NH and Schuppan D: Circulating microparticles as disease-specific biomarkers of severity of inflammation in patients with hepatitis C or nonalcoholic steatohepatitis. Gastroenterology 143(2): 448$458,2012$.

21 Zuwala-Jagiello J, Simon K, and Pazgan-Simon M: Elevated circulating endothelial cell-derived microparticle levels in patients with liver cirrhosis: a preliminary report. Clin Exp Hepatol 1(3): 105-111, 2015.

22 van Ierssel SH, Van Craenenbroeck EM, Conraads VM, Van Tendeloo VF, Vrints CJ, Jorens PG and Hoymans VY: Flow cytometric detection of endothelial microparticles (EMP): effects of centrifugation and storage alter with the phenotype studied. Thromb Res 125(4): 332-339, 2010.

23 Goon PK, Boos CJ, Stonelake PS, Blann AD and Lip GY: Detection and quantification of mature circulating endothelial cells using flow cytometry and immunomagnetic beads: a methodological comparison. Thromb Haemost 96(1): 45-52, 2006. 
24 Meckes DG Jr. and Raab-Traub N: Microvesicles and viral infection. J Virol 85(24): 12844-12854, 2011.

25 Diamant M, Nieuwland R, Pablo RF, Sturk A, Smit JW and Radder JK: Elevated numbers of tissue-factor exposing microparticles correlate with components of the metabolic syndrome in uncomplicated type 2 diabetes mellitus. Circulation 106(19): 2442-2447, 2002.

26 Guicciardi ME and Gores GJ: Apoptosis as a mechanism for liver disease progression. Semin Liver Dis 30(4): 402-410, 2010.

27 Violi F, Basili S, Raparelli V, Chowdary P, Gatt A and Burroughs AK: Patients with liver cirrhosis suffer from primary haemostatic defects? Fact or fiction? J Hepatol 55(6): 1415-1427, 2011.

28 Szotowski B, Antoniak S, Goldin-Lang P, Tran QV, Pels K, Rosenthal P, BogdanovVY, Borchert HH, Schultheiss HP and Rauch U: Antioxidative treatment inhibits the release of thrombogenic tissue factor from irradiation- and cytokineinduced endothelial cells. Cardiovasc Res 73(4): 806-812, 2007.

29 Essayagh S, Brisset AC, Terrisse AD, Dupouy D, Tellier L, Navarro C, Arnal JF and Sié P: Microparticles from apoptotic vascular smooth muscle cells induce endothelial dysfunction, a phenomenon prevented by beta3-integrin antagonists.Thromb Haemost 94(4): 853-858, 2005.

30 Li D, Jia H, Zhang H, Lv M, Liu J, Zhang Y, Huang T and Huang B: TLR4 signalinginduces the release of microparticles by tumor cells that regulate inflammatory cytokine IL-6 of macrophages via microRNA let-7b. Oncoimmunology 1(5): 687-693, 2012.

31 Ceriello A and Motz E: Is oxidative stress the pathogenic mechanism underlying insulin resistance, diabetes, and cardiovascular disease? The common soil hypothesis revisited. Arterioscler Thromb Vasc Biol 24(5): 816-823, 2004.
32 Suematsu M, Suzuki H, Delano FA and Schmid-Schönbein GW: The inflammatory aspect of the microcirculation in hypertension: oxidative stress, leukocytes/endothelial interaction, apoptosis. Microcirculation 9(4): 259-276, 2002

33 Mallat Z, Benamer H, Hugel B, Benessiano J, Steg PG, Freyssinet JM and Tedgui A: Elevated levels of shed membrane microparticles with procoagulant potential in the peripheral circulating blood of patients with acute coronary syndromes. Circulation 101(8): 841-843, 2000.

34 Wang Y, Chen LM and Liu ML: Microvesicles and diabetic complications - novel mediators, potential biomarkers and therapeutic targets. Acta Pharmacol Sin 35(4): 433-443, 2014.

35 Boulanger CM, Scoazec A, Ebrahimian T, Henry P, Mathieu E, Tedgui A and Mallat Z: Circulating microparticles from patients with myocardial infarction cause endothelial dysfunction. Circulation 104(22): 2649-2652, 2001.

36 Terrisse AD, Puech N, Allart S, Gourdy P, Xuereb JM, Payrastre $\mathrm{B}$ and Sié P: Internalization of microparticles by endothelial cells promotes platelet/endothelial cell interaction under flow. J Thromb Haemost 8(12): 2810-2819, 2010.

37 Jansen F, Yang X, Franklin BS, Hoelscher M, Schmitz T, Bedorf $\mathrm{J}$, Nickenig $\mathrm{G}$ and Werner N: High glucose condition increases NADPH oxidase activity in endothelial microparticles that promote vascular inflammation. Cardiovasc Res 98(1): 94-106, 2013.
Received July 20, 2017

Revised August 8, 2017

Accepted August 9, 2017 